\title{
Intracellular fate of bioresponsive poly(amidoamine)s in vitro and in vivo
}

\author{
Simon C.W. Richardson ${ }^{\mathrm{a}, *}$, Nicola G. Pattrick ${ }^{\mathrm{b}}$, Nathalie Lavignac ${ }^{\mathrm{c}}$, Paolo Ferruti ${ }^{\mathrm{d}}$, Ruth Duncan ${ }^{\mathrm{a}, *}$ \\ a School of Science, University of Greenwich, Central Avenue, Chatham Maritime, Kent, England, ME4 4TB, UK \\ b Centre for Polymer Therapeutics, Welsh School of Pharmacy, Cardiff University, Redwood Building, King Edward VII Av, Cardiff, CF10 3XF, UK \\ ${ }^{c}$ Medway School of Pharmacy, Universities of Kent and Greenwich, Central Avenue, Chatham Maritime, Kent, ME4 4TB, UK \\ ${ }^{\text {d }}$ Dipartimento di Chimica Organica e Industriale, Università di Milano, via Venezian 21, 20133 Milano, Italy
}

\section{A R T I C L E I N F O}

Article history:

Received 4 August 2009

Accepted 29 September 2009

Available online 12 October 2009

\section{Keywords:}

Endosomolytic polymer

Poly(amidoamine)

Subcellular fractionation

\begin{abstract}
A B S T R A C T
Linear poly(amidoamine)s (PAAs) have been designed to exhibit minimal non-specific toxicity, display pHdependent membrane lysis and deliver genes and toxins in vitro. The aim of this study was to measure PAA cellular uptake using ISA1-OG (and as a reference ISA23-OG) in B16F10 cells in vitro and, by subcellular fractionation, quantitate intracellular trafficking of ${ }^{125}$ I-labelled ISA1-tyr in liver cells after intravenous (i.v.) administration to rats. The effect of time after administration $(0.5-3 \mathrm{~h})$ and ISA1 dose $(0.04-100 \mathrm{mg} / \mathrm{kg})$ on trafficking, and vesicle permeabilisation ( $N$-acetyl-b-D-glucosaminidase $(N A G)$ release from an isolated vesicular fraction) were also studied. ISA1-OG displayed 60-fold greater B16F10 cell uptake than ISA23-OG. Passage of ISA1 along the liver cell endocytic pathway caused a transient decrease in vesicle buoyant density (also visible by TEM). Increasing ISA1 dose from $10 \mathrm{mg} / \mathrm{kg}$ to $100 \mathrm{mg} / \mathrm{kg}$ increased both radioactivity and NAG levels in the cytosolic fraction (5-10 fold) at $1 \mathrm{~h}$. Moreover, internalised ISA1 provoked NAG release from an isolated vesicular fraction in a dose-dependent manner. These results provide direct evidence, for the first time, of PAA permeabilisation of endocytic vesicular membranes in vivo, and they have important implications for potential efficacy/toxicity of such polymeric vectors.
\end{abstract}

(c) 2009 Elsevier B.V. All rights reserved.

\section{Introduction}

The majority of gene therapy clinical trials currently use viral vectors, and effective cytosolic delivery of all therapeutically important macromolecular drugs (e.g. small interfering ribonucleic acids (siRNAs), DNA, proteins, peptides) is still the major challenge restricting their clinical development. Even viral vectors have major limitations [1]. They can be immunogenic [2,3], may produce insertional mutagenesis (causing cancers such as leukaemia) [1], and their pharmacokinetics can be non-target specific. Although an attractive alternative, and despite more than 20 years of research and development, lack of clinically measurable success using polymeric non-viral vectors has diminished credibility of this approach. Such synthetic vectors often show poor transfection efficiency coupled with transient gene expression [3,4]. They can display an unfavourable pharmacokinetic profile with high levels of liver/lung capture $[5,6]$ and many have unacceptably toxicity $[4,7,8]$. Moreover most polyplexes are ultimately impractical to manufacture on an industrial scale and/or use clinically. Many of these problems are due to either the cationic charge of the polymers used [9] and/or lack of homogeneity of the products prepared. Acknowledged as a key

\footnotetext{
* Corresponding authors. Richardson is to be contacted at Tel.: +44 02083318207; fax: +4402083319805.

E-mail addresses: S.C.W.Richardson@greenwich.ac.uk (S.C.W. Richardson), Duncanr@cf.ac.uk (R. Duncan).
}

biological rate-limiting step for the development of effective biocompatible, polymer-based cytosolic delivery systems is still poorly efficient endosomal escape which precludes adequate and reproducible intracellular delivery (cytosolic or nuclear) of a therapeutic dose [10-12]. Rather than simply screening for in vitro therapeutic activity using libraries of novel vectors, there is a clear need for rational design based upon a fundamental understanding of material physico-chemical properties.

During the development of linear poly(amidoamine)s (PAAs) as pH-responsive endosomolytic polymers (Fig. 1) we identified specific structures and salt form (ISA23 $\cdot \mathrm{HCl}$ and ISA1 $\cdot \mathrm{HCl}$ ) that showed considerable promise [13-16]. These PAAs (ISA1 IC I0 $_{0}$ for B16 was $3.1 \pm$ $0.7 \mathrm{mg} / \mathrm{mL}$, ISA23 $\mathrm{IC}_{50}$ for B16 was $>5 \mathrm{mg} / \mathrm{mL}$ [13]) have relatively low toxicity compared to other polycationic vectors ( $>100$ fold less toxic than poly(ethyleneimine) (PEI $\left.\left(M_{\mathrm{w}} 70,000 \mathrm{~g} / \mathrm{mol}\right)\right)$ and poly-L-lysine $\left(\right.$ PLL $\left.M_{\mathrm{w}} 72,000 \mathrm{~g} / \mathrm{mol}\right)$ ), and the ability (ISA23 $\cdot \mathrm{HCl}$ ) to escape reticuloendothelial system (RES) clearance after intravenous (i.v.) administration allowing tumour targeting by the enhanced permeability and retention (EPR) effect [13]. Although cytosolic delivery of genes by ISA23 $\cdot \mathrm{HCl}[15]$, and the delivery of non-permeant protein toxins such as gelonin and ricin A chain by ISA1 $\cdot \mathrm{HCl}$ [16] has been demonstrated in vitro, titration studies which systematically varied PAA:toxin ratio showed that delivery efficiency was likely to be impractical for repeated clinical dosing.

Therefore, to guide the development of more effective PAA chemistries better able to promote rapid (within $<10 \mathrm{~min}$ ), transient, 


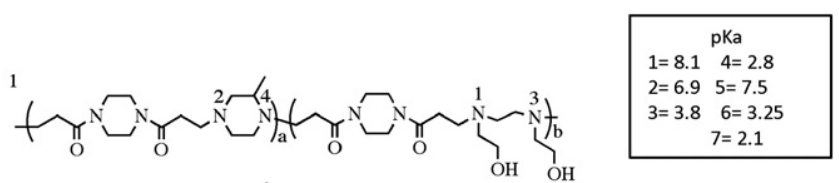<smiles>CC(=O)/C=C(\C)Oc1cc(O)cc(/C=C(/C)O)c1</smiles>

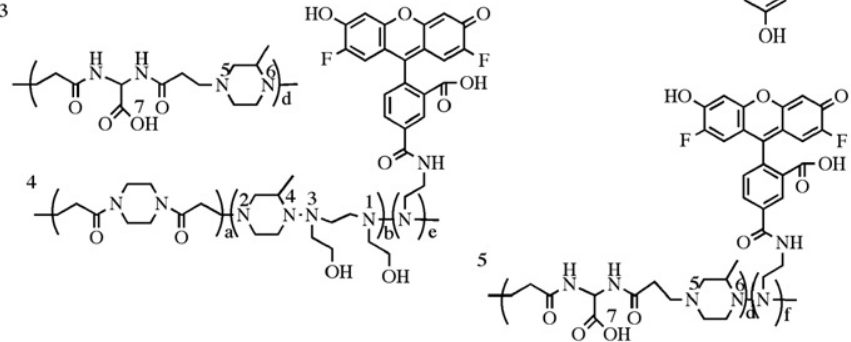

Fig. 1. Poly(amidoamine)s structures. ISA1 (1); ISA1-tyr (2); ISA23 (3); ISA1-OG (4); ISA23-OG (5).

and more efficient endosomal escape at pH 6.5 (Fig. 2a), we began to systematically define the physico-chemical properties of ISA23 and ISA1 (Fig. 1; Table 1). PAA shape, size, and pH-responsive changes in conformation were determined using small angle neutron scattering (SANS) $[17,18]$, and the rate of diffusion in solution was defined using pulsed-gradient spin-echo NMR [17]. Most recently PAA interaction with model micelles [19], and model membranes whose composition was chosen to mimic the plasma, endosomal and lysosomal membrane was measured using surface tension and electron plasmon resonance techniques in combination with SANS [19].

The aims of these studies were to define the endocytic uptake and intracellular trafficking of ISA1. First B16F10 cells (previously used to study PAA-mediated toxin delivery [16]), and ISA1-Oregon Green (OG) and ISA23-OG together with flow cytometry were used to quantitate uptake in vitro, and fluorescence microscopy was also used to visualise PAA and gelonin-Texas Red (TR) vesicular localisation over time. Subsequently liver subcellular fractionation was used to track the intracellular fate of ISA1 after intravenous (i.v.) to rats. Whereas the amphoteric ${ }^{125}$ I-labelled ISA23-tyr evades liver capture ( $<10 \%$ dose in the liver at $1 \mathrm{~h}$ ) after i.v. injection, the more cationic ${ }^{125}$ I-labelled ISA1-tyr displays substantial liver localisation ( $>80 \%$ dose, $1 \mathrm{~h}$ ) [13] thus providing a useful probe for these studies. Both time- and dose-dependent trafficking of ISA1 was quantified and the fractions obtained were also visualised by transmission electron microscopy (TEM). Cytosolic radioactivity levels were used to quantitate ${ }^{125}$ I-labelled ISA1-tyr endosomal escape and cytosolic $\mathrm{N}$-acetyl-b-D-glucosaminidase (NAG) release provided an indicator of PAA-induced vesicle permeabilisation. Following i.v. administration of increasing doses of ISA1, the ISA1-containing endosomal/ lysosome vesicles were isolated from rat liver and the in vitro release of NAG was measured over time. For comparison, the iso- (a)

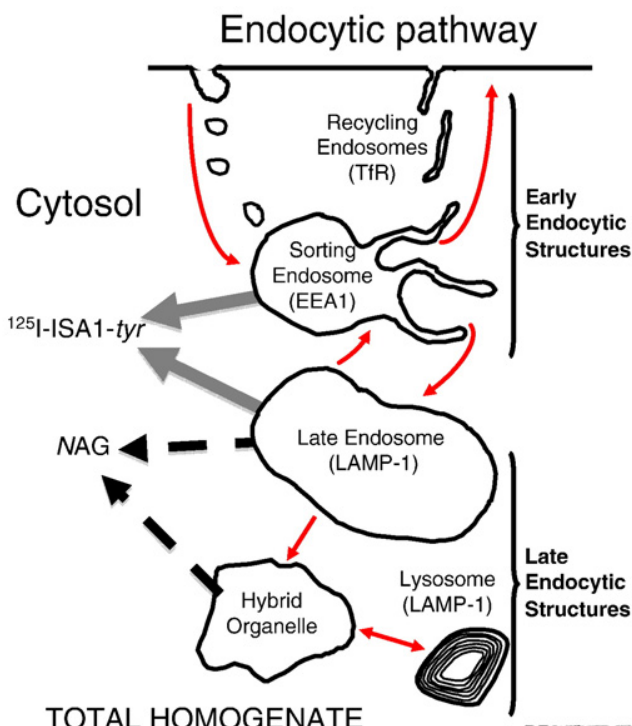

(b)

TOTAL HOMOGENATE

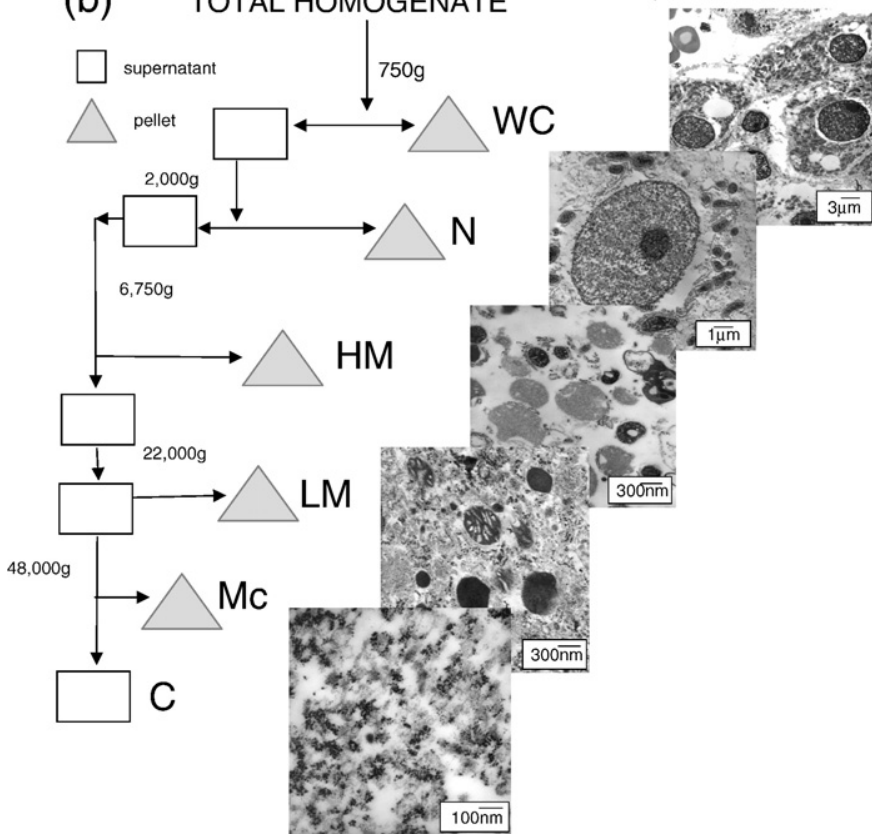

Fig. 2. Markers used and scheme showing methodology used for subcellular fractionation studies. Panel (a) simplified cartoon of the mammalian endocytic system and markers used in this study (modified from [33]). Panel (b) protocol used to perform differential centrifugation with inset TEMs of fractions obtained.

lated vesicle fraction was also incubated with ISA1 added to the culture medium (i.e. the outside). These experiments also allowed comparison with vesicle permeabilisation mediated by PEI and (N[1-(2,3-dioleoyloxy)propyl]-N,N,N,trimethylammonium methylsulfate) DOTAP $[20,21]$

\section{Materials and methods}

\subsection{Materials}

Polymers: ISA1, ISA1-tyr, ISA23 [13] and ISA1- $\mathrm{NH}_{2}$ and ISA23- $\mathrm{NH}_{2}$ (containing a terminal amine group) [22] were synthesised as previously described. The ISA1-tyr derivative was radio-iodinated and the PAA- $\mathrm{NH}_{2}$ derivatives bound to OG as described below. The chemical characteristics of all PAAs used in these studies are given (Fig. 1 and Table 1). PEI ( $\left.M_{\mathrm{n}} 70,000 \mathrm{~g} / \mathrm{Mol}\right)$ was from Sigma-Aldrich (Pool, UK).

General materials: These materials were from Sigma-Aldrich (Pool, UK) unless stated otherwise. PBS tablets were from Oxoid (Hampshire, UK), liquid nitrogen, carbon dioxide and oxygen were from BOC (Surrey, UK). PD10 columns and sodium [ ${ }^{125}$ I] iodide were from GE Healthcare (Chalfont St. Giles, UK). Dialysis membranes (14,000 g/mol cut-off), were from Millipore (Dundee, UK). 
Table 1

Characteristics of the PAAs and probes.

\begin{tabular}{|c|c|c|c|}
\hline Probe & $M_{\mathrm{w}}^{\mathrm{a}}(\mathrm{g} / \mathrm{mol})$ & Specific activity of OG/TR ( $\mu \mathrm{g} / \mathrm{mg}$ conjugate) or labelling efficiency (\%) & Free marker (\% total) \\
\hline ISA1-OG & 22,700 & 1.5 & $<5^{\mathrm{b}}$ \\
\hline ISA23-OG & 16,700 & 2.2 & $<5^{\mathrm{b}}$ \\
\hline ISA23 & 16,500 & NA & NA \\
\hline${ }^{125}$ I-labelled ISA1-tyr & 15,000 & 61.6 & $1.2 \%$ free $\left[{ }^{125} \mathrm{I}\right]$ iodide \\
\hline Gelonin-TR & 29,000 & 75 & $<5^{\mathrm{b}}$ \\
\hline
\end{tabular}

NA, not applicable.

a By gel permeation chromatography.

b Not detectable by TLC and or PD10 column chromatography.

In vitro assays: Anti-EEA1 monoclonal antibodies were from BD Bioscience (Oxford, UK), Vectorshield was from Vector Laboratories (Peterborough, UK), pioloform coated grids were from Agar Scientific (Essex, UK). Donkey anti-mouse conjugated Alexafluor 594, Texas Red (TR)-succinimide ester and Oregon Green (OG)-succinimide ester, RPMI medium, 4',6-diamidino-2-phenylindole (DAPI) foetal calf serum (FCS) and glutamate were from Invitrogen (Paisley, UK). B16F10 cells were from Prof. Ian Hart (St Thomas' Hospital, UK) [13].

In vivo experiments: Wistar rats were from Banton \& Kingman (Hull, UK) and isoflurane was from Abbott labs (Kent UK) and animal experiments carried out in accordance with UK Home Office Guidelines for Animal Experimentation.

\subsection{Methods}

\subsubsection{Synthesis and characterisation of PAA-OG probes (ISA1-OG and ISA23-OG) and ${ }^{125}$ I-labelled ISA1-tyr:}

ISA1- $\mathrm{NH}_{2}$ or ISA23- $\mathrm{NH}_{2}$ was dissolved (separately) in $5 \mathrm{~mL}$ sodium bicarbonate buffer $0.1 \mathrm{M} \mathrm{pH} 8$. The OG-succinimide ester (0.5 mg) was dissolved in $50 \mathrm{~mL}$ of DMSO and added to the polymer solution and left stirring at room temperature for $2 \mathrm{~h}$. Separation of ISA1-OG and ISA23-OG from the reaction products was achieved using PD10 columns followed by TLC analysis (using methanol) of the fractions to ascertain the purity of the conjugates prepared. For microscopy and polymer uptake analysis $1 \mathrm{mg} / \mathrm{mL}$ ISA1-OG and ISA23-OG and, where stated, the non-toxic concentration of $10 \mu \mathrm{g} / \mathrm{mL}$ gelonin was used [16].

Synthesis of Gelonin-TR: TR-succinimide ester $(0.5 \mathrm{mg})$ was dissolved in DMSO ( $50 \mu \mathrm{L})$. Gelonin $(1 \mathrm{mg})$ was dissolved in sodium bicarbonate buffer $0.1 \mathrm{M} \mathrm{pH} 8$ and stirred gently. The TR-succinimide ester was then added and the reaction was left for $2 \mathrm{~h}$ at room temperature in the dark. Separation of gelonin-TR from the reaction products was achieved using PD10 columns. The determination of free label in the purified product was conducted as before using TLC.

${ }^{125}$ I-labelled ISA1-tyr was prepared using sodium [ $\left.{ }^{125} \mathrm{I}\right]$ iodide and chloramine T as previously described [13]. Free sodium [ $\left.{ }^{125} \mathrm{I}\right]$ iodide was removed by exhaustive dialysis against sodium chloride $0.9 \% \mathrm{w} / \mathrm{v}$ and paper electrophoresis was used to assess labelling efficiency, specific activity and product purity.

\subsubsection{Fluorescence microscopy to visualise the uptake of ISA1-OG, ISA23-OG and gelonin-TR by B16F10 cells}

B16F10 cells in RPMI medium supplement with $10 \% \mathrm{v} / \mathrm{v}$ FCS and glutamate $(5 \mathrm{mM})$ were seeded in 6 wells plate $\left(1 \times 10^{6}\right.$ cells/well $)$ containing a sterile cover slip. After $24 \mathrm{~h}$ cells they were incubated with gelonin-TR, ISA1-OG, or ISA23-OG for the times and at the concentrations indicated. Cells were visualised directly in fresh complete media containing DAPI (300 nM) and red lysotracker dye (10 nM dissolved in DMSO) where indicated.

\subsubsection{Immunofluorescence microscopy}

B16F10 cells were prepared as above. After $24 \mathrm{~h}$ the medium was replaced by fresh medium containing ISA1-OG or ISA23-OG (10 mg/mL) and the cells were incubated at $37^{\circ} \mathrm{C}$ for $10 \mathrm{~min}$. Cover slips bearing adherent cells were then washed with PBS $(3 \times 5$ min washes at room temperature), and the cells were fixed in fresh paraformaldehyde ( $2 \% \mathrm{w} / \mathrm{v}$ (in PBS)) for $20 \mathrm{~min}$ at room temperature. The fixed cells were then washed three times in PBS ( 5 min each at room temperature), and then permeabilised and quenched using PBS containing Triton X-100 (0.02\% v/v) with glycine (50 mM). The cells were first incubated for 60 min at room temperature with primary anti-EEA1 monoclonal antibody (diluted 1:1000 in PBS containing bovine serum albumin ( $1 \% \mathrm{v} / \mathrm{v})$ and, after three washes in PBS, with the secondary antibody donkey-anti-mouse conjugated Alexafluor 594 also diluted 1:1000 in PBS containing bovine serum albumin $1 \% \mathrm{v} / \mathrm{v}$ ) for $60 \mathrm{~min}$ at room temperature. After 3 additional 5 min washes in PBS at room temperature, the cover slips were mounted using Vectashield (Vector Laboratories) containing DAPI (300 nM) and imaged using an SP5 scanning confocal microscope (Leika; Wetzlar, Germany).

\subsubsection{Flow cytometry}

B16F10 cells in RPMI medium supplemented with FCS $(10 \% \mathrm{v} / \mathrm{v})$ and glutamate $(5 \mathrm{mM})$ were seeded in 12 well plates $\left(1 \times 10^{5}\right.$ cells/well). After $24 \mathrm{~h}$, the medium was replaced with $1 \mathrm{~mL}$ of fresh, complete media containing either ISA1-OG or ISA23-OG $(10 \mu \mathrm{g} / \mathrm{mL})$ and the cells were incubated at $37^{\circ} \mathrm{C}$ or $4{ }^{\circ} \mathrm{C}$ (these cells were pre-incubated at $4{ }^{\circ} \mathrm{C}$ for $30 \mathrm{~min}$ before adding the PAA solution) for the times indicated. At each time point the cells were rinsed 3 times with ice-cold PBS, harvested by scraping with a sterile rubber policeman and analysed by flow cytometry. Untreated cells were used as a reference control and in each case 10,000 events were acquired. All experiments were carried out 4 times and the results expressed as:

$$
\text { cell-associated fluorescence }=\frac{\text { percentage positive cells } \times \text { mean fluorescence }}{100} .
$$

2.2.5. Determination of the intracellular trafficking of ${ }^{125}$ I-labelled ISA1 in rat liver cells-effect of time and dose

Male Wistar rats $(\sim 250 \mathrm{~g})$ were anaesthetised with isoflurane $(2 \% \mathrm{v} / \mathrm{v})$ and $\mathrm{O}_{2}(4 \% \mathrm{v} / \mathrm{v})$. A mixture of ${ }^{125} \mathrm{I}$-labelled-ISA1-tyr $\left(5 \times 10^{5} \mathrm{cpm}\right.$ in sterile saline) and non-radiolabelled ISA1 added to give the dose required $(0.04 \mathrm{mg} / \mathrm{kg}$ to $100 \mathrm{mg} / \mathrm{kg})$ was then injected into the caudal vein of the tail [13]. Rats were killed at various time points (30-180 min), the liver removed, rinsed in pre-chilled $\left(4{ }^{\circ} \mathrm{C}\right)$ sucrose $(250 \mathrm{mM})$ and blotted 
dry before weighing. The liver was then cut into $3-5 \mathrm{~mm}^{3}$ cubes with scissors (on ice), forced through a wire mesh (1 mm ${ }^{3}$ ) and the crude homogenate was re-suspended in a $2.5 \mathrm{~mL}$ ice-cold fractionation buffer (sucrose $250 \mathrm{mM}$ containing EDTA1 mM) per g of liver. This crude homogenate was further homogenised using a Potter-Elvehjem homogeniser $(0.019 \mathrm{~cm}$ clearance; $5 \times 10 \mathrm{~s}$ up and down strokes at $3000 \mathrm{rpm})$ (ThermoFisher Scientific, Hampshire, UK) and the resultant homogenate was weighed and a $1 \mathrm{~mL}$ sample was removed and frozen in liquid nitrogen for use during subsequent analyses. This fraction was denoted the total homogenate fraction ( $\mathrm{H}$ fraction).

\subsubsection{Subcellular fractionation of rat liver}

The protocol used for fractionation of isolated liver cells is summarised in Fig. 2b. Unless otherwise stated all centrifugation steps were performed at $4{ }^{\circ} \mathrm{C}$. The total $\mathrm{H}$ fraction was centrifuged at $750 \times \mathrm{g}$ for $2 \mathrm{~min}$ and the pellet (intact cells) was re-suspended in ice-cold sucrose (250 mM; $2 \mathrm{~mL}$ ), weighed, $1 \mathrm{~mL}$ removed and frozen (WC fraction). The decanted supernatant was also weighed, and $1 \mathrm{~mL}$ was removed and snap frozen.

The remaining supernatant was then centrifuged at $2000 \times \mathrm{g}$ for $2 \mathrm{~min}$ and the resulting pellet was re-suspended in $5 \mathrm{~mL}$ of ice-cold fractionation buffer before re-centrifugation at $2000 \times \mathrm{g}$ for $2 \mathrm{~min}$ to wash the pellet. The final pellet was re-suspended in $2 \mathrm{~mL}$ of fractionation buffer, weighed and a $1 \mathrm{~mL}$ aliquot was frozen. This was denoted the nuclear fraction ( $\mathrm{N}$ fraction). The resulting supernatants from the first $2000 \times g$ centrifuge step and the wash (also at $2000 \times g$ step) were pooled and centrifuged at $6750 \times g$ for 4 min. The supernatant and the pellet were again separated and the pellet was washed. The supernatants obtained were combined, and the final pellet was re-suspended in $5 \mathrm{~mL}$ of fractionation buffer, weighed, and a $1 \mathrm{~mL}$ aliquot was frozen. This fraction was denoted the heavy mitochondrial fraction (HM fraction).

The combined supernatants were centrifuged at 22,000 $\times g$ for $9 \mathrm{~min}$. As above, the pellet was washed and the final pellet was re-suspended in $5 \mathrm{~mL}$ of fractionation buffer and weighed before a $1 \mathrm{~mL}$ aliquot was removed and snap frozen. This was denoted the light mitochondrial fraction (LM fraction). Finally the combined supernatants from this step were centrifuged at $48,000 \times \mathrm{g}$ for 70 min, to obtain a pellet which was resuspended in $2 \mathrm{~mL}$ of fractionation buffer and denoted the microsomal fraction (MC fraction). The final supernatant represented the cytosolic/ soluble fraction ( $\mathrm{C}$ fraction). Again, both fractions were weighed and aliquots were snap frozen in liquid nitrogen. All fractions were kept at $-20{ }^{\circ} \mathrm{C}$ until assayed for biochemical markers as described below and, where appropriate for radioactivity using a RioGamma 1240 counter (LKBWallac; Victoria, Australia). Where \% values pertaining to radioactivity recovery occur in the text, reference is made to \% total counts per min $(\mathrm{cpm})$ recovered.

\subsubsection{Characterisation of subcellular fractions}

Where necessary fractions were diluted with PBS to ensure assays could be related to the linear range of the respective calibration curve.

Protein assay: BCA reagent ( $200 \mathrm{~mL}$ of a mixture of $\mathrm{CuSO}_{4}$ pentahydride $4 \% \mathrm{w} / \mathrm{v}$ and bicinchoninic acid at a ratio of $1: 50$ ) was added to fraction samples (10 mL; in triplicate) and was incubated at room temperature for $30 \mathrm{~min}$. Bovine serum albumin (BSA) standards $(\sim 2-50 \mu \mathrm{g} / \mathrm{mL}) \mathrm{were}$ used to calibrate this assay. Results were expressed as protein $(\mathrm{mg} / \mathrm{mL})$ in each fraction and also related, as a percentage, to the total recovered protein from all the fractions.

$N$-acetyl-b-D-glucosaminidase assay: NAG was measured using an assay adapted from [23]. $50 \mu \mathrm{L}$ of each fraction, $250 \mu \mathrm{L}$ sodium-citrate buffer ( $0.2 \mathrm{M} \mathrm{pH} 5.0$, containing Triton X-100 $0.1 \%(\mathrm{v} / \mathrm{v})$ ) and the sample were warmed to $37^{\circ} \mathrm{C}$. Then the substrate 4-methylumbelliferyl-Nacetamido- $\beta$-D-glucosaminide $(100 \mu \mathrm{L} ; 10 \mathrm{mM})$ in sucrose $(0.25 \mathrm{M})$ was added and the mixture was incubated at $37{ }^{\circ} \mathrm{C}$ for $1 \mathrm{~min}$. Sodium bicarbonate ( $3 \mathrm{~mL} ; 1 \mathrm{M}$ ) was added to stop the reaction, and activity was assessed fluorometrically (emission at $450 \mathrm{~nm}$ and excitation $365 \mathrm{~nm}$ ).

Transmission electron microscopy (TEM) of isolated fractions: The LM fraction was prepared from rat liver after i.v. injection of saline (control) or ISA1 treatment $(25 \mathrm{mg} / \mathrm{kg})$ as described above. Samples were fixed for $45 \mathrm{~min}$ at $4{ }^{\circ} \mathrm{C}$ using a $1: 2 \mathrm{v} / \mathrm{v}$ solution of glutaraldehyde (2.5\% w/v) and osmium tetroxide $(1 \% \mathrm{w} / \mathrm{v})$. The fixed fractions were briefly washed in sodium cacodylate buffer $(0.2 \mathrm{M}$; $\mathrm{pH} 7.2)$, before rinsing in distilled water for $45 \mathrm{~min}$. They were stained with uranyl acetate $(0.5 \% \mathrm{w} / \mathrm{v})$ for $30 \mathrm{~min}$, before dehydration $(3 \times 10 \mathrm{~min}$ washes $)$ in a graded series of $50-100 \% \mathrm{v} / \mathrm{v}$ acetone solutions. Finally, the samples were embedded in araldite resin and incubated at $37^{\circ} \mathrm{C}$ overnight. Thin sections were cut and placed onto pioloform coated grids and they were counterstained with $0.5 \% \mathrm{w} / \mathrm{v}$ uranyl acetate and $0.5 \% \mathrm{w} / \mathrm{v}$ lead citrate for $10 \mathrm{~min}$. Samples were visualised using 201 and 208 TEM microscopes (Philips, Eindhoven, The Netherlands).

\subsubsection{Measurement of NAG release from isolated rat liver vesicles incubated with ISA1 outside or containing ISA1 inside}

To investigate the effect of ISA1 on vesicle membrane permeability when added outside, a LM fraction was first prepared from rat liver as described above. The vesicles were resuspended in sucrose-EDTA containing $\mathrm{HCl}(0.1 \mathrm{M})$ and a $2 \mathrm{~mL}$ sample was incubated with ISA 1 , (0.5 mL; concentration $0-2 \mathrm{mg} / \mathrm{mL})$ in saline $(0.9 \% \mathrm{w} / \mathrm{v})$ or saline containing Triton X-100 $(0.2 \% \mathrm{w} / \mathrm{v})$ at $37{ }^{\circ} \mathrm{C}$ (Fig. $8 \mathrm{c}$ ). At various times aliquots $(50 \mu \mathrm{L})$ were removed and assayed for NAG activity as described above. The results were expressed as a percentage lysis compared to the Triton X-100 control.

In parallel experiments the effect of ISA1 internalised into liver endocytic vesicles on membrane integrity was investigated. First, ISA1 (doses from 0 to $50 \mathrm{mg} / \mathrm{kg}$ in sterile saline) was injected i.v. into the tail vein of anaesthetised rats. After 30 min the animals were killed, the liver was taken, and subcellular fractionation was undertaken as described above to obtain the LM fraction. This vesicular fraction was then re-suspended in $1 \mathrm{~mL}$ ice-cold fractionation buffer. As above, aliquots $(50 \mu \mathrm{L})$ were removed at various times, and assayed for NAG activity as described above.

\subsubsection{Data presentation}

The distribution of NAG and radioactivity in the fractions was expressed as a percentage of the total recovered in all fractions. A vesicle stability index (VSI) was also calculated using the following formula:

Percentage NAG or radioactivity in the HM fraction + Percentage NAG or radioactivity in text LM fraction Percentage $N A G$ or radioactivity in the C fraction

The higher the VSI, the greater vesicular stability.

Statistical significance was calculated using the Student's $t$-test for small sample sizes with the aid of Prism QuickCalcs ${ }^{\mathrm{TM}}$ software from Graphpad Inc. (San Diego, CA). 


\section{Results}

3.1. Uptake and intracellular trafficking of PAA-OG conjugates in B16F10 cells in vitro

The ISA1-OG, ISA23-OG conjugates and gelonin-TR used contained only a minimal amount of free fluorophore (Table 1; Fig. 3). Fluorescence microscopy revealed little gelonin-TR uptake by B16F10 cells after $5 \mathrm{~h}$ (Fig. 4a panels $\mathrm{i}$ and ii) and a similar picture was seen at $24 \mathrm{~h}$ (data not shown). However, when added in combination with ISA1-OG, gelonin-TR uptake was dramatically increased (Fig. 4a panels iii-iv), and in many cases the vesicles seen displayed a red 'halo' consistent with gelonin-TR release into the cytosol. The inset (Fig. 4a panel v) shows a typical magnified profile. Lysotracker, labelling of acidic endo-lysosomes revealed some degree of co-localisation with ISA1-OG and this was most evident in small puncta located within the cell cortex (Fig. 4a panels vi-viii). Although ISA23-OG also showed co-localisation with lysotracker (Fig. 4a panels ix-xi), unlike ISA1, this PAA did not enhance gelonin-TR uptake. Indeed, the pattern of cellular fluorescence observed when incubated with the combination was similar to that seen in cells incubated with toxin alone (Fig. 4a panels ix-xi). Cells incubated with ISA1-OG for $10 \mathrm{~min}$ and subsequently probed with an antibody (labelled red) to EEA-1 (Fig. 4b panel i) showed EEA-1 co-localisation of ISA1-OG (Fig. 4b panel ii and arrows depicting co-localisation in individual vesicles are shown in Fig. 4b panel iii).

Comparison of the uptake of ISA1-OG and ISA23-OG by B16F10 cells using flow cytometry indicated that both PAAs displayed a similar degree of non-specific binding at $4{ }^{\circ} \mathrm{C}$ (Fig. 5). However, whereas increasing incubation temperature to $37^{\circ} \mathrm{C}$ led to a marked increase in cell association/uptake of ISA1-OG this was not seen for ISA23-OG. Indeed the uptake of ISA1-OG was $~ 60$ times greater.

\subsection{Subcellular fate of ${ }^{125}$ I-labelled ISA1-tyr in liver cells after i.v. injection}

The liver fractionation procedure used was reproducible in terms of both the protein and NAG distribution and the range of RSA of protein and NAG obtained for each fraction are shown in Table 2. The total recovery achieved for protein was $\sim 100 \%$ and for NAG was $~ 80 \%$. TEM confirmed the anticipated morphology of the fractions prepared (Fig. 2). Importantly, the ${ }^{125}$ I-labelled ISA1-tyr probe used contained a minimal amount of free $\left[{ }^{125} \mathrm{I}\right]$ iodide $(1.2 \%$ (total cpm)) (Fig. 6a; Table 1$)$.

In the first experiment, $1 \mathrm{~h}$ after injection of a tracer dose $(0.04 \mathrm{mg} / \mathrm{kg})$ of ${ }^{125}$ I-labelled ISA1-tyr most radioactivity and NAG (Fig. 6b) were detected in the HM fraction (72-73\%). When nonradiolabelled ISA1 was added to this tracer to increase the dose administered to 10 and $100 \mathrm{mg} / \mathrm{kg}$ respectively, it was shown that as the dose increased the distributions of both recovered radioactivity and NAG changed markedly. The radioactivity recovered in the HM fraction at $60 \mathrm{~min}$ fell from $73.1 \%$ to $42.8 \%$ at $10 \mathrm{mg} / \mathrm{kg}$ and then to $40.8 \%$ at $100 \mathrm{mg} / \mathrm{kg}$. Concomitantly, there was a small increase in radioactivity detected in the LM fraction. Most importantly, there was also a significant increase in the radioactivity recovered in the $\mathrm{C}$ fraction; rising from $2 \%$ at $0.04 \mathrm{mg} / \mathrm{kg}$ to $19.5 \%$ (10 mg/kg) and $16.2 \%$ (100 mg/kg) (Fig. 6c).

The NAG distribution also changed significantly. At the lowest dose $72.3 \%$ of the NAG activity in the HM fraction was documented (Fig. 6d). Increasing ISA1 dose to $10 \mathrm{mg} / \mathrm{kg}$ caused a fall in NAG

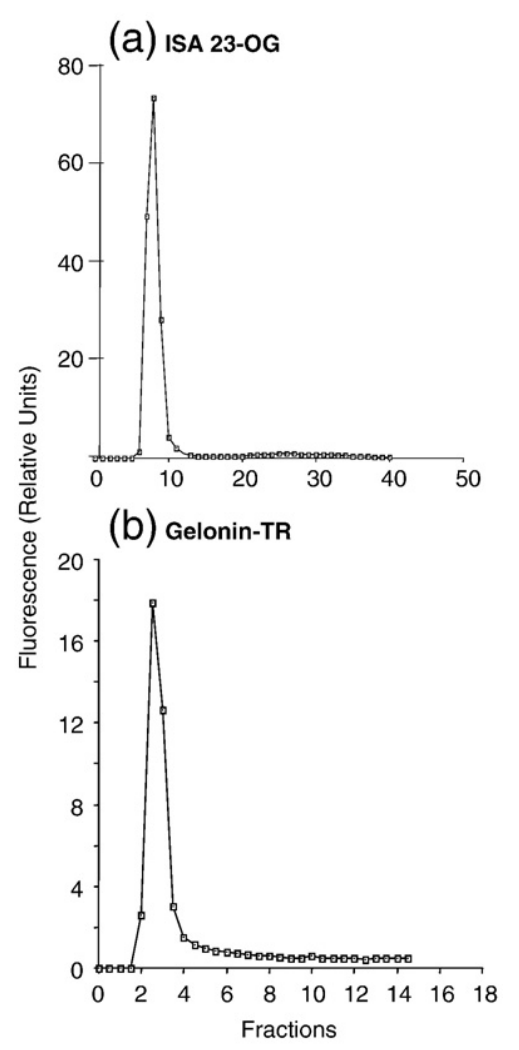

Fig. 3. Typical PD10 chromatography profiles for ISA23-OG and gelonin-TR showing purity of probes used for fluorescence microscopy (Fig. 4).

recovery in the HM fraction to $25.8 \%$ accompanied by a significant redistribution into the LM fraction where NAG levels rose to $55.7 \%$ from a baseline of $19.4 \%$. As seen for the radioactivity redistribution, this transfer of NAG between HM and LM fractions was accompanied by a statistically significant increase in NAG, from $2.5 \%$ at low dose to $10.4 \%$ at $10 \mathrm{mg} / \mathrm{kg}$, in the $\mathrm{C}$ fraction (Fig. $6 \mathrm{~d}$ ). Interestingly, when ISA1 dose was increased to $100 \mathrm{mg} / \mathrm{kg}$, the NAG distribution in the HM (79.5\%) and LM (5.8\%) fractions reverted to a pattern similar to that seen at the lowest dose. However, it was noteworthy that cytosolic levels remained higher at $~ 10.3 \%$ (Fig. $6 \mathrm{~d}$ ). The effect of ISA1 dose on the cytosolic transfer of radioactivity and NAG can be clearly seen when the data are expressed as a VSI (Fig. 6e).

When the liver fractionation was conducted at various times after the i.v. administration of ISA1 $(10 \mathrm{mg} / \mathrm{kg})$ the distribution of both radioactivity and NAG changed over time (Fig. 7). At $30 \mathrm{~min}$ radioactivity (Fig. 7a) and NAG (Fig. 7b) were primarily associated with the HM fraction. However by $60 \mathrm{~min}$ distribution of both markers shifted from the HM into the LM fraction. The NAG redistribution was most striking with the LM level of $3.7 \%$ at $30 \mathrm{~min}$ rising to a level of $55.7 \%$ at $60 \mathrm{~min}$. Interestingly by $120 \mathrm{~min}$ there was a return of NAG distribution to predominantly the HM fraction with levels in the LM fraction falling to $12.0 \%$ where it remained (12.4\%) at $180 \mathrm{~min}$ (Fig. 7a). Between $30 \mathrm{~min}$ and $60 \mathrm{~min}$ NAG cytosolic levels increased from $3.9 \%$ to $10.4 \%$. These $\mathrm{C}$ fraction NAG levels remained at $\sim 10 \%$ over the rest of the time course (Fig. 7a).

Although the recovered radioactivity in the HM fraction remained highest throughout the time course, radioactivity detected in the LM

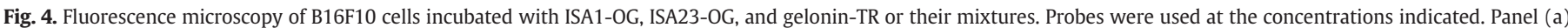

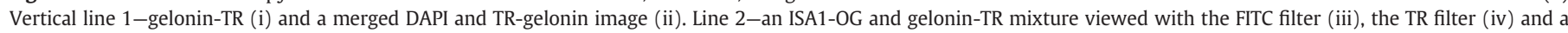

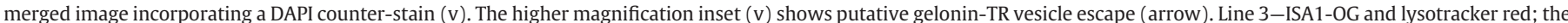

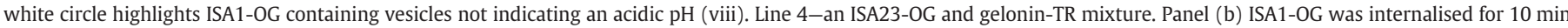

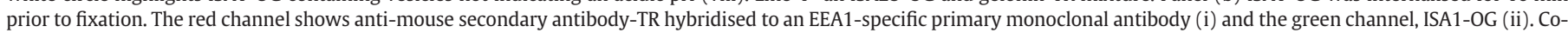
localisation is indicated by arrows in (iii). The size bar represents $5 \mu \mathrm{m}$. 
FITC filter

(a) B16F10 cells (5h)

TR filter
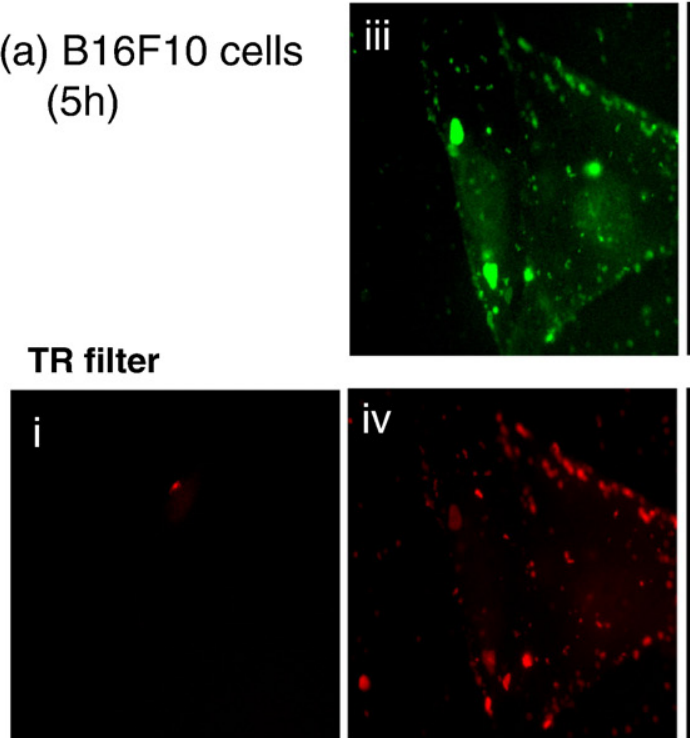

\section{Merge}

ii
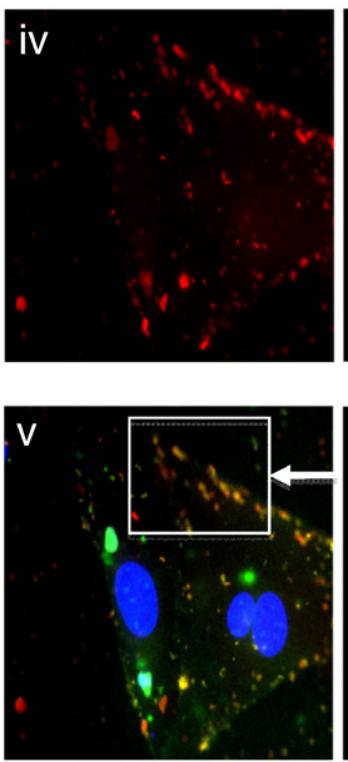

$10 \mu \mathrm{g} / \mathrm{mL}$ gelonin-TR
$1 \mathrm{mg} / \mathrm{mL}$ ISA 1OG and 10 $\mu \mathrm{g} / \mathrm{mL}$ geloninTR
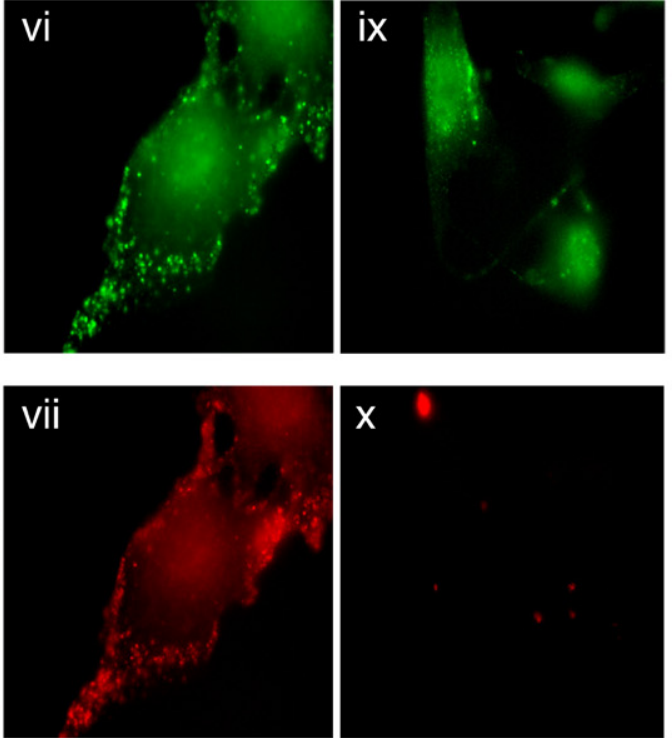

X
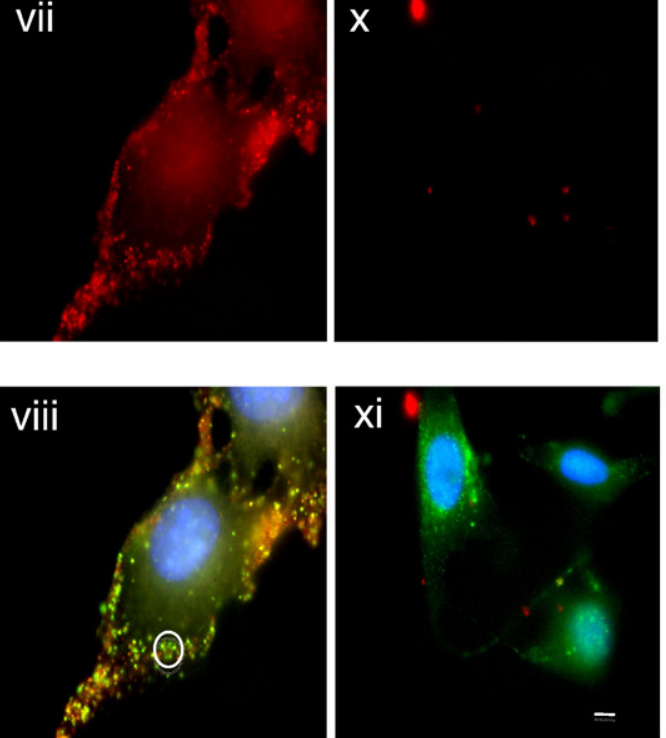

xi

$1 \mathrm{mg} / \mathrm{mL}$ ISA 1$O G$ and $200 \mathrm{nM}$ lysotracker

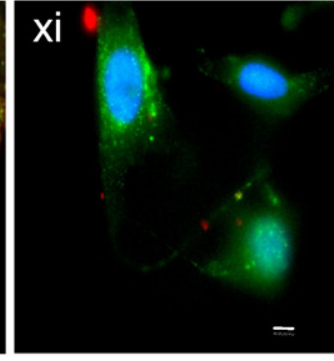

$1 \mathrm{mg} / \mathrm{mL}$ ISA 23-OG and $10 \mu \mathrm{g} / \mathrm{ml}$ gelonin-TR

(b) B16F10 cells (10 min)
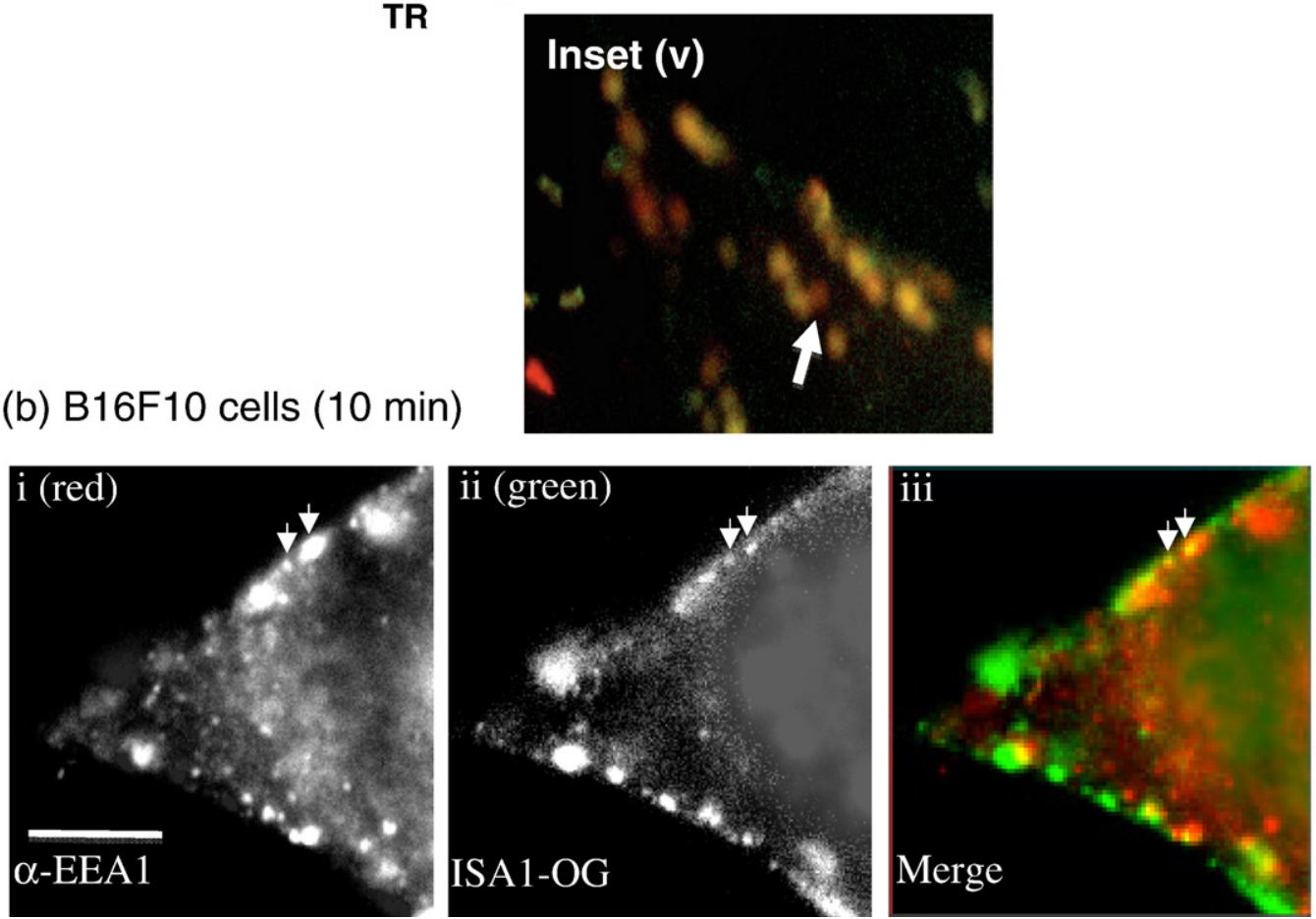


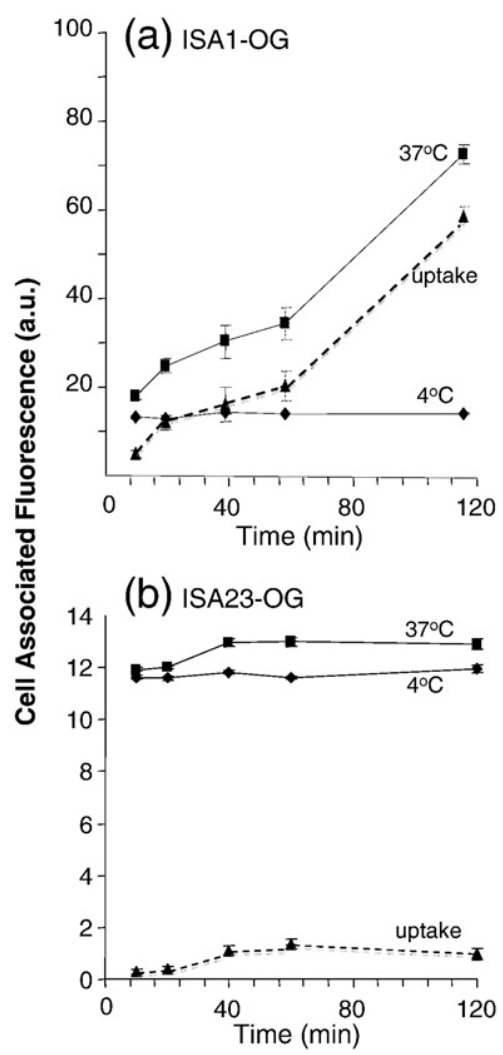

Fig. 5. Uptake of PAA-OG by B16F10 cells in vitro assessed by flow cytometry. Panel (a) ISA1-OG and (b) ISA23-OG. Cells were incubated at the temperatures shown and "uptake" estimated by subtracting values obtained at $4{ }^{\circ} \mathrm{C}$. Data represent mean \pm S.D. $(n=3)$.

fraction did also increase; from $7.0 \%$ at $30 \mathrm{~min}$ to $21.0 \%$ at $60 \mathrm{~min}$. As for NAG, these LM radioactivity levels fell again at 120 and $180 \mathrm{~min}$; in this case to $11 \%$. Cytosolic radioactivity was $5.3 \%$ at $30 \mathrm{~min}$ and although it did rise to $19.5 \%$ at 60 min levels detected at 120 and 180 min fell back to $6.2 \%$ and $4.1 \%$ respectively. Again the VSI underlined cytosolic entry (Fig. 7c) with the lower index indicating increased membrane permeability.

TEM indicated that the vesicles isolated from rat liver after i.v. injection of ISA1 were markedly different in appearance being larger and swollen compared to the more electron-dense vesicles isolated from rats injected with saline (Fig. 7a,b). These observations were consistent with the increased buoyant density of the vesicles containing NAG and radioactivity at $60 \mathrm{~min}$ after injection of ISA1.

\subsection{ISA1 permeabilisation of vesicles in vitro and ex vivo}

Isolated liver cell vesicles were incubated in a medium designed to minimise osmotic breakage in vitro even the controls showed 15-20\% free NAG at the start of the experiment. This was unlikely caused by the buffer as previous research has shown that a lysosome-rich fraction from rat liver normally exhibits latency with respect to enzyme activity in the range of $10-20 \%$ of the total activity in that fraction for several hours after its isolation. Addition of increasing concentrations of ISA1 to the incubation mixture caused no significant increase in NAG release after $45 \mathrm{~min}$ or $2 \mathrm{~h}$ (Fig. 8c) (ISA 23 also showed no significant NAG release in this assay; results not shown). In contrast, addition of PEI did induce $\mathrm{pH}$-dependent release of NAG (Fig. 8d) indicating vesicle membrane destabilisation.

When ISA1-containing vesicles were isolated from liver after prior i.v. injection of the PAA NAG release over time was however observed.
Table 2

Characterisation of the liver subcellular fractions.

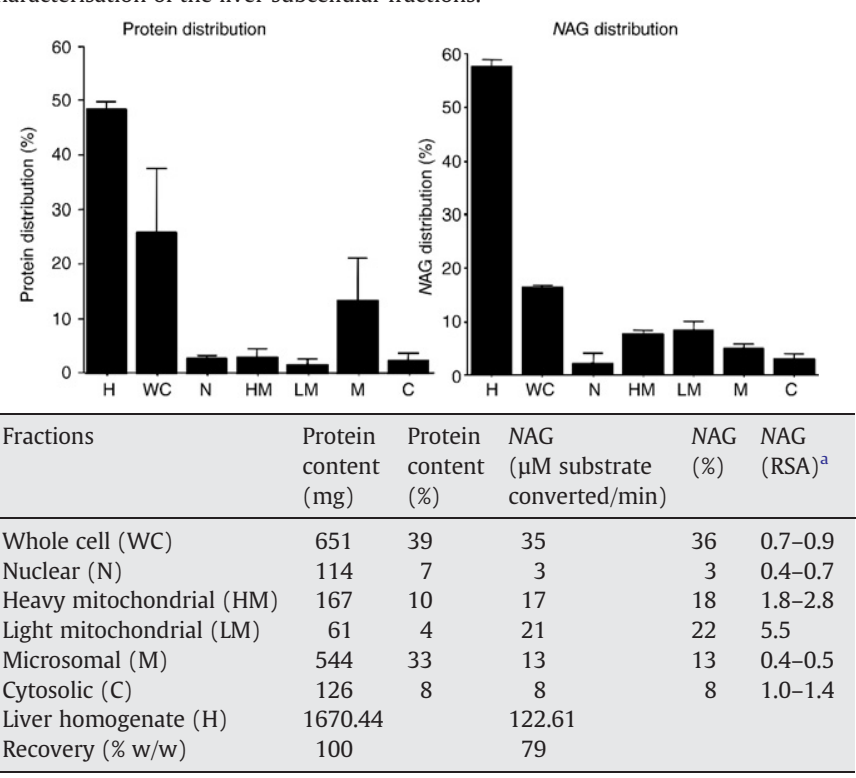

a RSA; The relative specific activity calculated by dividing the percentage distribution of NAGase by the fractional percentage distribution of protein in each fraction.

The extent of release was dose-dependent (Fig. 8d). For example, $10 \mathrm{mg} / \mathrm{kg}$ ISA1 did not significantly elevate NAG release relative to the control, but release was a 3-fold higher ( $2 \mathrm{~h}$ ) after administration of an ISA1 dose of $50 \mathrm{mg} / \mathrm{kg}$. These observations were compatible with the ISA1-induced increase in cytosolic NAG seen in the earlier subcellular fractionation studies (Figs. 6 and 7).

\section{Discussion}

Previous PAA-mediated cytotoxicity assays showed that ISA1 could deliver the non-permeant protein toxins gelonin and ricin $A$ chain into the cytosol resulting in cytotoxicity [16]. In contrast ISA23 could not. Evaluation of a library of PAAs having different monomer composition led us to suggest [24], as others have done for other polymers $[25,26]$, that PAA endosomolytic activity was not simply attributable to proton sponge effect. We postulate that intracellular vesicle permeabilisation involves physical PAA-membrane interaction. Consistent with this hypothesis are previously reported studies in the red blood cell (RBC) haemolysis model, which showed that PAAs added to RBCs cause pH-dependent haemoglobin release depending on their chemical composition and salt form [13,14,24].

In an attempt to better understand mechanistically the reasons for the differences in ISA1- and ISA23-mediated toxin delivery first experiments defined the cell uptake of both using OG-labelled PAAs. Flow cytometry showed that ISA1-OG uptake was much more rapid ( 60 fold) than seen for ISA23-OG (Fig. 5a). This would presumably lead to a much higher intravesicle concentrations of ISA1 and the temperature-dependency of cell association was indicative of an active process. (It is noteworthy that previous studies with OGlabelled polymers have shown both stability of the conjugate (little or no OG release over a $2 \mathrm{~h}$ incubation) and minimal $\mathrm{pH}$ - or concentration-dependent OG fluorescence quenching [27].) Endocytic internalisation of ISA1-OG by B16F10 cells in vitro was confirmed visually by fluorescence microscopy (Fig. 4). The higher uptake of ISA1-OG compared to ISA23 is not surprising as, at neutral $\mathrm{pH}$, this cationic PAA will interact with anionic plasma membrane components and thus display adsorptive rather than solely fluid-phase endocytosis. In comparison at neutral pH ISA23 carries a net negative charge. The low levels of cell interaction observed at $4{ }^{\circ} \mathrm{C}$ and indeed minimal internalisation at $37^{\circ} \mathrm{C}$ (Fig. 5) suggest little membrane 

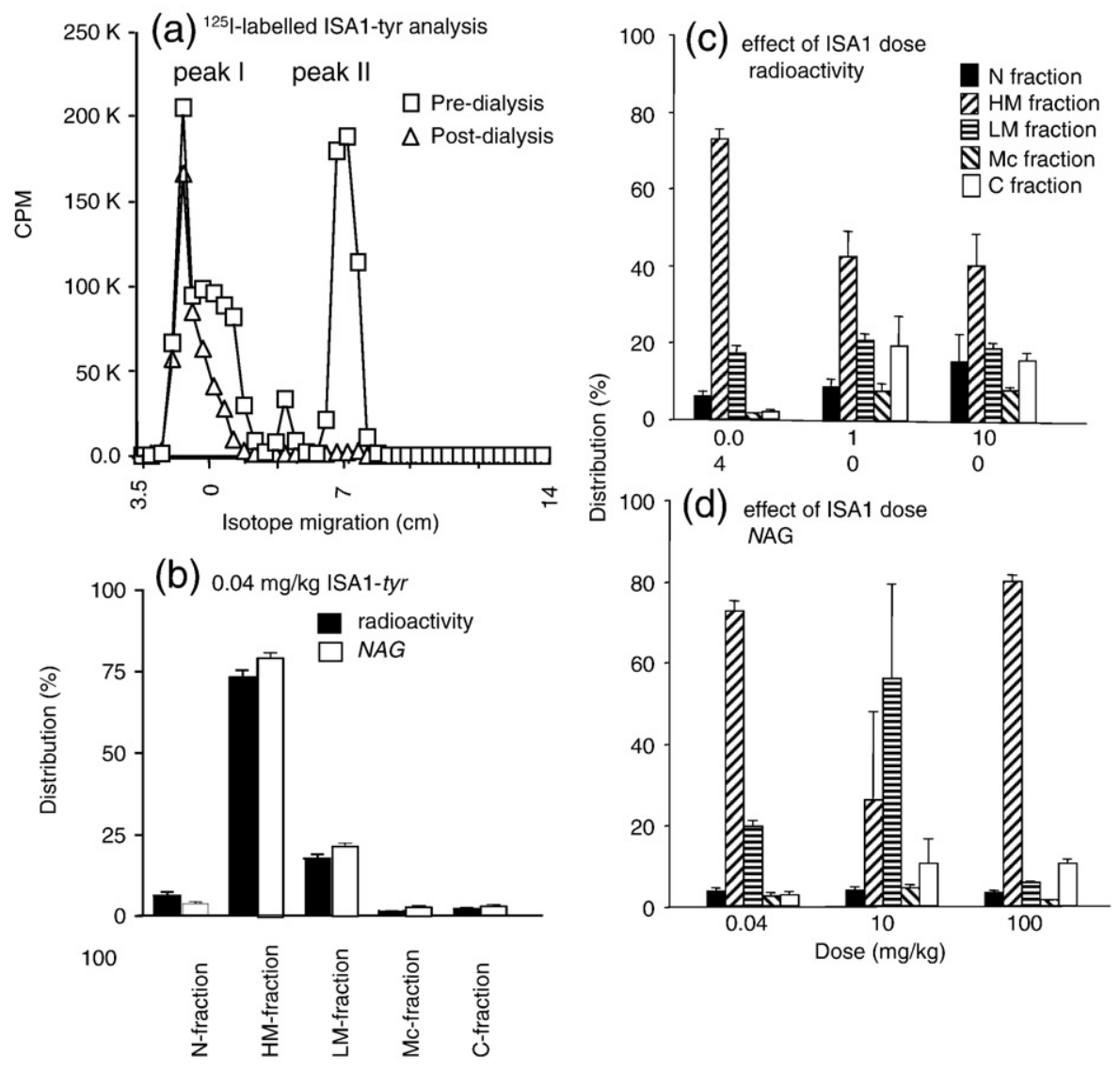

(e) Lysosomal Stability Index

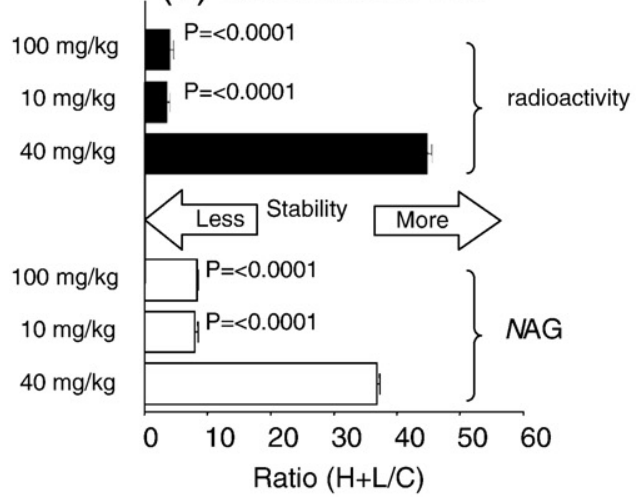

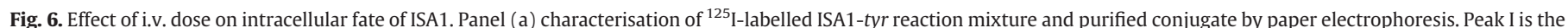

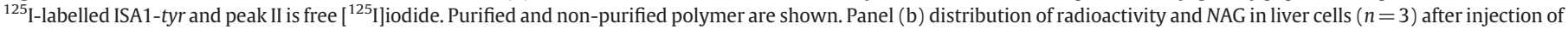

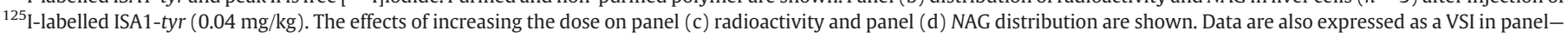
the lower the ratio the greater the vesicle permeability (e). $P$-values denote the statistical difference compared to the $0.04 \mathrm{mg} / \mathrm{kg}$ dose. Data represent mean \pm S.D. ( $n=3$ ).

interaction. Previously reported SANS studies showed that ISA23 coil expansion resulting from polymer backbone protonation only occurred at pH 5 and below, pH values not normally associated with the endosomal compartment [18].

Although potentially interesting, further dissection of the endocytic pathways utilised by these PAAs in vitro was not undertaken as such studies are likely to be irrelevant to increased understanding intracellular fate in vivo. The endocytic process is complex, and both trafficking pathways and vesicle $\mathrm{pH}$ are cell type-dependent [28] so general conclusions regarding entry mechanisms and intracellular fate of lipoplexes and polyplexes are impossible to make [29]. Moreover, many use a combination of fluorescent-labelled vectors and/or payload with chemical inhibitors (reviewed in [30]) to gain clues as to trafficking pathways knowing that these studies are additionally complicated by the fact that many inhibitors are not uniquely pathway-specific. Such compounds exert non-specific toxicities themselves so data require careful interpretation [30]. Roles for glycosaminoglycans, cell polarization and cell cycle have been proposed but all do vary from one cell type to another [28]. Nevertheless it has been suggested, and seems likely, that intracellular trafficking, rather than degree of uptake or cytotoxicity, may be the most important factor for cytosolic delivery [31].

Although fluorescence microscopy gives only a qualitative perspective, here it was clear that co-incubation of ISA1 with gelonin-TR resulted in much greater cell uptake of gelonin-TR. Furthermore, many vesicle profiles along the edge of the B16F10 cells displayed a red halo at the vesicle margin (denoted by an arrow in Fig. 4a panel v) suggesting gelonin-TR release into the cytosol facilitated by PAA- 


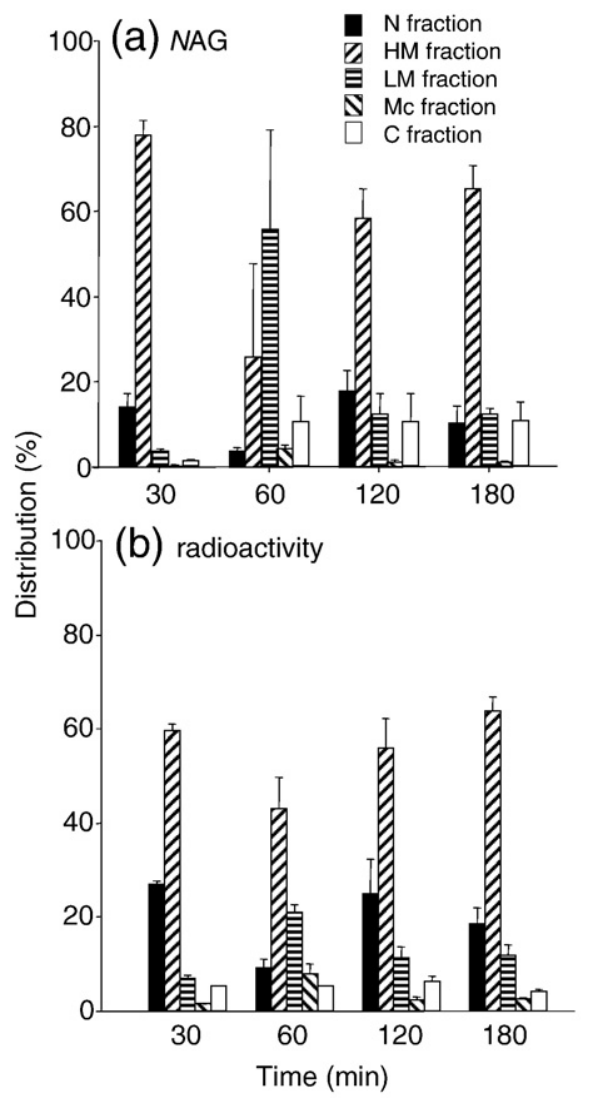

(c) Lysosomal Stability Index

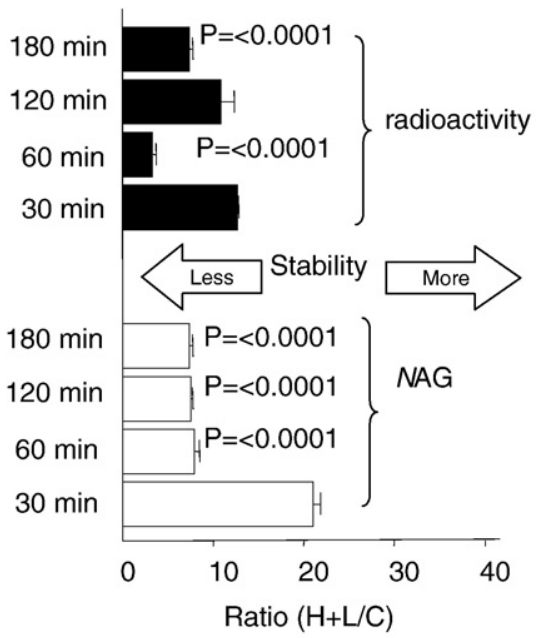

and panel (c) VSI. Data represent mean \pm S.D. $(n=3)$.

mediated permeabilisation. Interestingly, these vesicle profiles were very similar to those seen during studies on the intracellular fate of PEI-ribozyme complexes where the release from vesicles visualised using video scanning laser confocal microscopy was described as a "sudden event, very likely due to bursting of these organelles" [32]. The co-localisation of ISA1-OG with the early endosomal marker EEA1 (Fig. 4b), and our previous studies have shown that B16F10 internalised markers localise to an EEA1 positive and transferrin receptor positive early endosomes after $\sim 5-10$ min [33] suggest that gelonin-TR release seen in Fig. 4a occurs from an early endosomal compartment.

When intracellular trafficking of ISA1 in liver cells was quantified using the ${ }^{125}$ I-labelled ISA1-tyr probe, endocytic internalisation of PAA in vivo was confirmed for the first time. Interestingly, although both were principally recovered in the HM and LM fractions, the distribution of ISA1 (radioactivity) and NAG showed both time- and dose-dependent changes in their intracellular distribution. Two very important features emerged.

First was the transfer of radioactivity and NAG into the cytosolic fraction over time indicating vesicle permeabilisation. These effects were ISA1 dose-dependent. There was 2-fold more radioactivity $(\sim 20 \%)$ in the cytosolic fraction at 60 min than NAG ( 10\%) (Fig. 6) but this level did not increase with time which might be suggestive either of transient permeabilisation and/or that radiolabelled-ISA1 interacts with and remains associated with the interior face of the lysosomal membrane. The NAG release observed ( 10\% the total enzyme activity) has important implications for the design and use of a PAA-based cytosolic delivery system. In a positive sense this observation verifies that ISA1 can disrupt the lysosomal membrane sufficiently to enable a protein of molecular weight $71,000 \mathrm{~g} / \mathrm{mol}$ to escape. Albeit that $90 \%$ of NAG remained associated with the organelle fractions, release could be a concern in the context of potential acute/ chronic toxicity. Few authors acknowledge that non-viral vectors designed to permeabilise intracellular vesicle membranes can be inherently harmful if they induce either catastrophic intracellular vesicle rupture (acute toxicity) or low level, but sustained, perturbation of the normal physiological functioning of the endosomal/ lysosomal apparatus. Prolonged leakage of lysosomal enzymes would endanger cell viability and may cause other undesirable patho-physiological changes.

The second, and an important observation arising from these subcellular fractionation studies, was the redistribution of the lysosomal marker NAG and radioactivity from the HM to LM fractions over the first $60 \mathrm{~min}$ with a subsequent return to the baseline distribution after 180 min (Figs. 6 and 7). Internalisation of ISA1 delayed trafficking leading to transient accumulation of vesicles with increased buoyant density (profiles seen also by TEM; Fig 8a,b). This is likely due to inhibition of entry into the late endosome-lysosome hybrid organelle [34] where enzymatic digestion occurs [35]. It is possible that ISA1 membrane interaction inhibits vesicle fusion, and/or causes an efflux of hydrogen ions resulting in an increased vesicular luminal $\mathrm{pH}$ and halting the continued destabilisation of the membrane by ionized (and now de-protonating) PAAs. Interestingly fluorescence microscopy showed ISA1-OG also within vesicles that appeared to be in non-acidic i.e. none-lysotracker positive (Fig. 4 panel vii). Alternatively, buffering of the late endosome $\mathrm{pH}$ by ISA1 would inhibit vesicle-vesicle fusion which is thought to be dependent upon vesicular $\mathrm{pH}$ regulated by the V-ATPase [36,37] or lysosomal reformation [34]. These observations were consistent with those of Wattiaux and colleagues who showed, using liver subcellular fractionation, that $\left[{ }^{35} \mathrm{~S}\right]$ plasmid-containing lipoplexes [38] and poly-lysine polyplexes [39] exhibited a delay ( $>5 \mathrm{~h}$ in the case of lipoplexes) in trafficking to lysosomes (arylsulfatase positive vesicles) compared to control probes present there at $1 \mathrm{~h}$. Their poly-L-lysine-containing polyplexes 


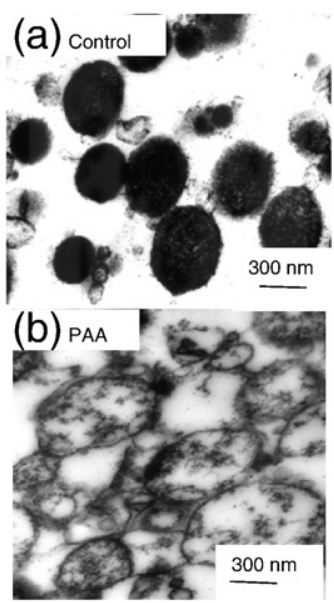

(d) NAG release from isolated vesicles

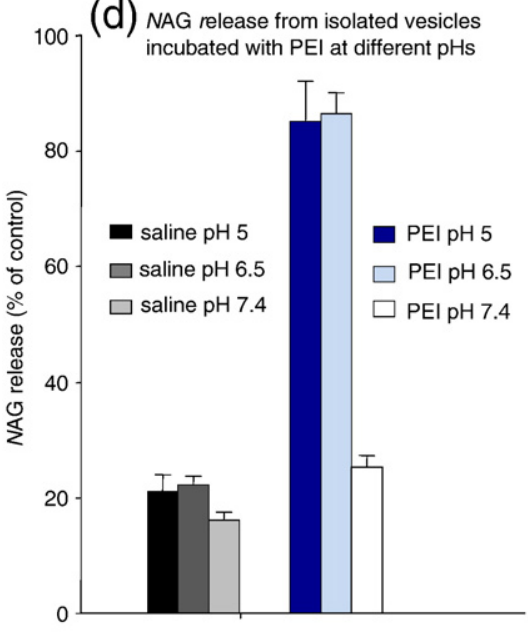

(C) NAG release from isolated vesicles incubated with concentrations of ISA 1

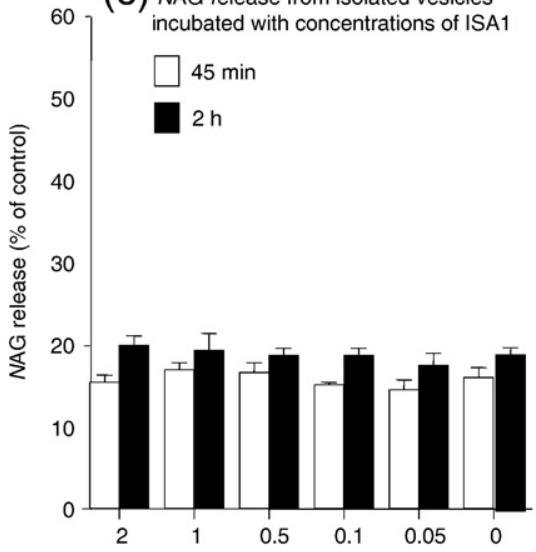

ISA1 concentration (mg/ml)

(e) NAG release from isolated vesicles containing ISA 1

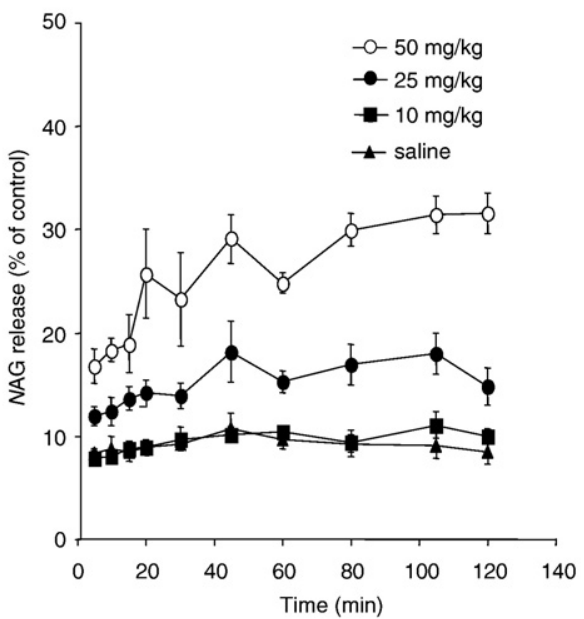

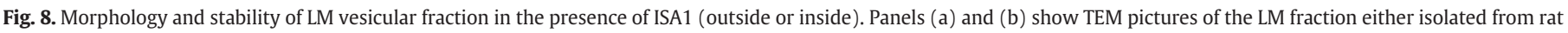

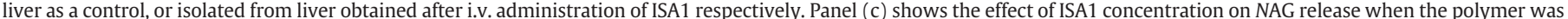

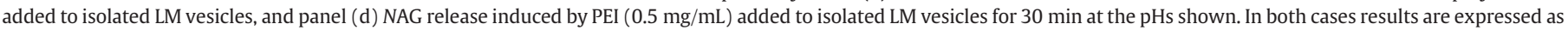

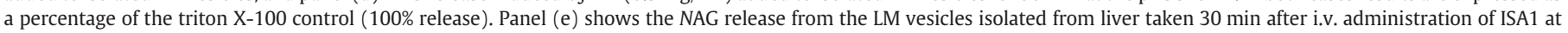
doses shown. Data represent mean \pm S.D. $(n \mathrm{~h}=3)$.

trafficked faster than poly-D-lysine polyplexes, even though both were endocytosed at the same rate and it was suggested that the digestion of the vector in a pre-lysosomal compartment is required to allow endocytosed plasmid DNA to rapidly reach lysosomes [39]. Whatever the mechanism(s) the time dependency suggests that the biological effects of ISA1 are transient, but it is clear that they are also dose-dependent.

There was a lack of electron density within the swollen membranedelimited structures containing ISA1 (Fig. 8b) and as the outer membranes can be seen it is possible that ISA1 is interacting with the inner leaflet causing pore formation driven by the protonation of the PAAs backbone. The studies on lysosomal latency clearly demonstrated that, unlike PEI which shows pH-dependent lysosomal membrane permeabilisation when added to the outside of a vesicular fraction, ISA1 needs to interact with the luminal as opposed to the cytosolic membrane leaflet to promote NAG release (Fig. $8 \mathrm{c}$ and d) and that permeabilisation is dose-dependent. The fact that PEI and DOTAP [21] cause significant release of lysosomal enzymes when added to the outside of isolated vesicles, although less pronounced at $\mathrm{pH} 7.4$, is indicative of the potential to design PAAs that will display more selective, and specific endosomal escape mechanism. Tuning the physico-chemical properties of PAAs to increase the speed of membrane permeabilisation whilst minimising lysosomal enzyme escape and perturbation of the endocytic pathway should give vectors with an optimal safety/efficacy profile in vivo.

\section{Acknowledgements}

NP would like to thank Dr. A. Hann for his help with the TEM work and BBSRC for a committee PhD Studentship. SCR would like to thank the EPSRC platform (EP/C013220/1) and Greenwich Research and Enterprise (GRE) for their generous support.

\section{References}

[1] M.H. Porteus, J.P. Connelly, S.M. Pruett, A look to future directions in gene therapy research for monogenic diseases, PLoS Genet. 2 (9) (2006) e133.

[2] T. Kielian, W.F. Hickey, Inflammatory thoughts about glioma gene therapy, Nature Med. 5 (1999) 1237-1238.

[3] M. Morille, C. Passirani, A. Vonarbourg, A. Clavreul, J.P. Benoit, Progress in developing cationic vectors for non-viral systemic gene therapy against cancer, Biomaterials 24/25 (2008) 3477-3496.

[4] S. Chokaskulnimitr, S. Masuda, H. Tokuda, Y. Takakura, M. Hashida, In vitro cytotoxicity of macromolecules in different cell culture systems, J. Control. Release 34 (1995) 233-241.

[5] M. Nishikawa, Y. Takakura, M. Hashida, Pharmacokinetic considerations regarding non-viral cancer gene therapy, Cancer Sci. 99 (5) (2008) 856-862. 
[6] M. Nishikawa, Y. Takakura, M. Hashida, Pharmacokinetics of plasmid DNA-based non-viral gene medicine, Adv. Genet. 53 (2005) 47-68.

[7] D. Lew, S.E. Oarker, T. Latimer, A. Kuwaharararundell, S.G. Doh, Z.Y. Yang, D. Laface, S.H. Gromkowski, G.J. Nabel, M. Manthorpe, J.L. Norman, Cancer gene therapy using plasmid DNA pharmacokinetic study of DNA following injection in mice, Hum. Gene Ther. 1 (1995) 553-564.

[8] A. Katchalsky, D. Danon, A. Nevo, A. De Vries, Interactions of basic polyelectrolytes with the red blood cell. II: agglutination of red blood cells by polymeric bases, Biochim. Biophys. Acta 33 (1959) 120-138.

[9] U. Lungwitz, M. Breunig, T. Blunk, A. Göpferich, Polyethylenimine-based non-viral gene delivery systems, Eur. J. Pharm. Biopharm. 60 (2) (2005) 247-266.

[10] D. Lechardeur, G.L. Lukack, Intracellular barriers to non-viral gene transfer, Curr. Gene Ther. 2 (2) (2002) 183-194.

[11] C. Plank, B. Oberhauser, K. Mechtler, C. Koch, E. Wagner, The influence of endosome-disruptive peptides on gene transfer using synthetic virus-like gene transfer systems, J. Biol. Chem. 269 (1994) 12918-12924.

[12] A. Kichler, K. Mechtler, J.-P. Behr, E. Wagner, Influence of membrane-active peptides on lipospermine / DNA complex mediated gene transfer, Bioconjug. Chem. 8 (1997) 213-221.

[13] S.C.W. Richardson, P. Ferruti, R. Duncan, Poly(amidoamine)s as potential endosomolytic polymers: evaluation in vitro and body distribution in normal and tumour bearing animals, J. Drug Target. 6 (1999) 391-404.

[14] K.W. Wan, B. Malgesini, I. Verpilio, P. Ferruti, P.C. Griffiths, A. Paul, A.C. Hann, R. Duncan, Poly(amidoamine) salt form: effect on pH-dependent membrane activity and polymer conformation in solution, Biomacromolecules. 5 (3) (2004) 1102-1109.

[15] S.C.W. Richardson, N.G. Pattrick, Y.K. Stella Man, P. Ferruti, R. Duncan, Poly (amidoamine)s as potential nonviral vectors: ability to form interpolyelectrolyte complexes and to mediate transfection in vitro, Biomacromolecules 2 (2001) 1023-1028.

[16] N.G. Pattrick, S.C.W. Richardson, S. Manzoni, P. Ferruti, R. Duncan, Poly (amidoamine)mediated intracytoplasmic delivery of ricin A-chain and gelonin, J. Control. Release 77 (2001) 225-232.

[17] Z. Khayat, P.C. Griffiths, I. Grillo, R.K. Heenan, S.M. King, R. Duncan, Characterising the size and shape of polyamidoamines in solution as a function of $\mathrm{pH}$ using neutron scattering and pulsed-gradient spin-echo NMR, Int. J. Pharm. 317 (2006) 175-186.

[18] P. Griffiths, A. Paul, Z. Khayat, K. Wan, S. King, I. Grillo, R. Schweins, P. Ferruti, J. Franchini, R. Duncan, Understanding the mechanism of action of poly(amidoamine)s as endosomolytic polymers: correlation of physicochemical and biological properties, Biomacromolecules 5 (4) (2004) 1422-1427.

[19] P. Griffiths, Z. Khayat, S. Tse, R. Heenan, S. King, R. Duncan, Studies on the mechanism of interaction of a bioresponsive endosomolytic polyamidoamine with interfaces. 1. Micelles as model surfaces, Biomacromolecules 8 (3) (2007) 1004-1012.

[20] A.R. Klemm, D. Young, J.B. Lloyd, Effects of polyethyleneimine on endocytosis and lysosome stability, Biochem. Pharmacol. 56 (1998) 41-46.

[21] R. Wattiaux, M. Jadot, M.T. Warnier-Pirotte, S. Wattiaux-De Coninck, Cationic lipids destabilize lysosomal membrane in vitro, FEBS Lett. 417 (2) (1997) 199-202.

[22] B. Malgesini, I. Verpilio, R. Duncan, P. Ferruti, Poly(amido-amine)s carrying primary amino groups as side substituents, Macromol. Biosci. 3 (1) (2003) 59-66.

[23] J. Barret, M.F. Heath, Lysosomal Enzymes, in: J.T. Dingle (Ed.), Lysosomes: A Laboratory Handbook, 2nd Edition, Elsevier/North-Holland Biomedical Press, Amsterdam, 1977, pp. 19-145.
[24] P. Ferruti, S. Manzoni, S.C.W. Richardson, R. Duncan, N.G. Pattrick, R. Mendichi, M Casolaro, Amphoteric linear poly(amidoamine)s as endosomolytic polymers: correlation between physico-chemical and biological properties, Macromolecules 21 (2000) 7793-7800.

[25] P. van de Wetering, E.E. Moret, N.M. Schuurmans-Nieuwenbroek, M.J. van Steenbergen, W.E. Hennink, Structure-activity relationships of water-soluble cationic methacrylate/methacrylamide polymers for nonviral gene delivery, Bioconjug. Chem. 10 (4) (1999) 589-597.

[26] A.M. Funhoff, C.F. van Nostrum, G.A. Koning, N.M. Schuurmans-Nieuwenbroek, D.J. Crommelin, W.E. Hennink, Endosomal escape of polymeric gene delivery complexes is not always enhanced by polymers buffering at low pH, Biomacromolecules 5 (1) (2004) 32-39.

[27] F.P. Seib, A.T. Jones, R. Duncan, Endocytic behaviour of linear, branched PEI and cationic PAMAM dendrimers in B16F10 melanoma cells, J. Control. Release 17 (2007) 291-300.

[28] G.J. Doherty, H.T. McMahon, Mechanisms of endocytosis, Ann. Rev. Biochem. 78 (2009) 857-902.

[29] P. Midoux, G. Breuzard, J.P. Gomez, C. Pichon, Polymer-based gene delivery: a current review on the uptake and intracellular trafficking of polyplexes, Curr. Gene Ther. 8 (5) (2008) 335-352.

[30] A.I. Ivanov, Pharmacological inhibition of endocytic pathways: is it specific enough to be useful? Methods Mol. Biol. 440 (2008) 15-33.

[31] Y. Saito, S. Kawakami, Y. Yabe, F. Yamashita, M. Hashida, Intracellular trafficking is the important process that determines the optimal charge ratio on transfection by galactosylated lipoplex in HEPG2 cells, Biol. Pharm. Bull. 29 (9) (2006) 1986-1990.

[32] T. Merdan, K. Kunath, D. Fischer, J. Kopecek, T. Kissel, Intracellular processing of poly(ethylene imine)/ribozyme complexes can be observed in living cells by using confocal laser scanning microscopy and inhibitor experiments, Pharm. Res. 19 (2) (2002) 140-146.

[33] S.C.W. Richardson, K.-L. Wallom, E.L. Ferguson, S.P.E. Deacon, M. Davies, A.J. Powell, R. Piper, R. Duncan, The use of fluorescence microscopy to define polymer conjugate localisation to late endocytic compartments in cells that are targets for drug delivery, J. Control Release 127 (2008) 1-11.

[34] R.C. Piper, J.P. Luzio, CUPpling calcium to lysosomal biogenesis, Trends Cell Biol. 14 (9) (2004) 471-473.

[35] B.M. Mullock, N.A. Bright, C.W. Fearon, S.R. Gray, J.P. Luzio, Fusion of lysosomes with late endosomes produces a hybrid organelle of intermediate density and is NSF dependent, J. Cell Biol. 140 (3) (1998) 591-601.

[36] C. Lafourcade, K. Sobo, S. Kieffer-Jaquinod, J. Garin, F.G. van der Goot, Regulation of the V-ATPase along the endocytic pathway occurs through reversible subunit association and membrane localization, PLoS 3 (7) (2008) e2758.

[37] H.Uchiyama Kawai, S. Takano, N. Nakamura, S. Ohkuma, Autophagosomelysosome fusion depends on the $\mathrm{pH}$ in acidic compartments in $\mathrm{CHO}$ cells, Autophagy. 3 (2) (2007) 154-157.

[38] R. Wattiaux, M. Jadot, N. Laurent, F. Dubois, S. Wattiaux-De Coninck, Cationic lipids delay the transfer of plasmid DNA to lysosomes, Biochem. Biophys. Res. Commun. 227 (1996) 448-454.

[39] N. Laurent, S. Wattiaux-De Coninck, E. Mihaylova, E. Leontieva, M.T. WarnierPirotte, R. Wattiaux, M. Jadot, Uptake by rat liver and intracellular fate of plasmid DNA complexed with poly-L-lysine or poly-D-lysine, FEBS Lett. 443 (1999) 61-65. 